Bull. Mater. Sci., Vol. 36, No. 3, June 2013, pp. 483-490. (c) Indian Academy of Sciences.

\title{
Optimization of process parameter for synthesis of silicon quantum dots using low pressure chemical vapour deposition
}

\author{
DIPIKA BARBADIKAR, RASHMI GAUTAM ${ }^{\dagger}$, SANJAY SAHARE ${ }^{\dagger}$, RAJENDRA PATRIKAR ${ }^{\dagger}$ and \\ JATIN BHATT* \\ Department of Metallurgical and Material Engineering, ${ }^{\dagger}$ Department of Electronics Engineering, Visvesvaraya National \\ Institute of Technology, Nagpur 440 010, India
}

MS received 9 August 2011; accepted 2 April 2013

\begin{abstract}
Si quantum dots-based structures are studied recently for performance enhancement in electronic devices. This paper presents an attempt to get high density quantum dots (QDs) by low pressure chemical vapour deposition (LPCVD) on $\mathrm{SiO}_{2}$ substrate. Surface treatment, annealing and rapid thermal processing (RTP) are performed to study their effect on size and density of QDs. The samples are also studied using Fourier transformation infrared spectroscopy (FTIR), atomic force microscopy (AFM), scanning electron microscopy (SEM) and photoluminescence study (PL). The influence of $\mathrm{Si}-\mathrm{OH}$ bonds formed due to surface treatment on the density of QDs is discussed. Present study also discusses the influence of surface treatment and annealing on QD formation.
\end{abstract}

Keywords. Annealing; AFM; LPCVD; thin film; quantum dot.

\section{Introduction}

According to Knoss (2009), quantum dots (QDs) are small devices that contain tiny droplets of free electrons and hence the energy levels in QDs are quantized due to quantum confinement. Semiconductor QD represents nanoscale system with few electrons confined in semiconductor host crystal, thus when excited, they emit light at a characteristic wavelength. Wavelength of light emitted depends on size of the dots. The importance of semiconductor QDs lies primarily in their tunability and sensitivity to external parameters as electrons are confined in all the three dimensions. As a result, they have properties in between bulk semiconductor and discrete molecules. QDs show quantum confinement effect and Coulomb blockade effect which is responsible for excellent optical and electrical properties. Owing to the above properties, QDs are used in LEDs (Soon et al 2009), diode lasers (Grundmann et al 1998), solar cells (Adachi 2007), sensors (Zhao et al 2009) and as floating gate in flash memory cells (Geller et al 2008). The reliability of devices depends on controlling size of QD and obtaining their uniformity. There are different techniques like hot wire chemical vapour deposition (Pant and Russell 2001), low pressure chemical vapour deposition (Makihara et al 2005), plasma enhanced chemical vapour deposition (Mercaldo et al 2009) by which $\mathrm{Si}$ QDs can be deposited on $\mathrm{SiO}_{2}$ substrate. Wiesmann et al (1979) reported that $a-\mathrm{Si}: \mathrm{H}$ can be formed by cracking silane gas molecules on hot tungsten foil. Matsumura (1986) used silane and hydrogen gas mixture to obtain Si thin film and Pant and Russell (2001)

\footnotetext{
*Author for correspondence (jatinbhatt@mme.vnit.ac.in)
}

studied effect of process parameters on Si QD. Recent studies indicate use of LPCVD for Si QD deposition (Miyazaki et al 2000; Makihara et al 2005). Earlier work carried out in this area is to improve density, reduce size and increase the uniformity of QD formed. In the present investigation, $\mathrm{Si}$ QDs are prepared by LPCVD using very low pressure of the order of 0.2 torr to deposit uniform silicon thin film on $\mathrm{SiO}_{2}$ substrate at $550{ }^{\circ} \mathrm{C}$. Optimization of surface treatment is carried out to increase the density of Si QDs. Comparative study of luminescence property of QDs formed and its dependence on the size and density are also discussed. Moreover, effect of RTP on size of QD after surface treatment and prior to LPCVD is studied.

\section{Experimental}

\subsection{Initial sample preparation}

$4^{\prime \prime} p$ type Si wafer of (100) orientation, $4-7 \Omega \mathrm{cm}$ resistivity and polished on one side was taken initially and cleaned. The polished wafers were then oxidized to form $\mathrm{SiO}_{2}$ by dry oxidation at $1000{ }^{\circ} \mathrm{C}$ in $\mathrm{O}_{2}$ and $\mathrm{H}_{2}$ atmosphere with gas flow rate 6000 and $8000 \mathrm{sccm}$, respectively for $20 \mathrm{~min}$ at atmospheric pressure.

\subsection{Surface treatment}

$\mathrm{SiO}_{2}$ substrate was subjected to surface treatment in order to form $\mathrm{Si}-\mathrm{OH}$ bonds which further acted as nucleating sites for deposition of QDs. To optimize surface treatment, $\mathrm{SiO}_{2}$ substrate was dipped into $0 \cdot 1,0.3$ and $0.5 \% \mathrm{HF}$ solution for 
Table 1. FTIR peak position of $\mathrm{Si}-\mathrm{O}-\mathrm{Si}$ stretching in different samples dipped in HF solution of different concentration for varying time and their ellipsometry results.

\begin{tabular}{|c|c|c|c|c|c|}
\hline $\begin{array}{l}\text { Sr. } \\
\text { No }\end{array}$ & $\begin{array}{c}\% \mathrm{HF} \\
\text { solution }\end{array}$ & $\begin{array}{l}\text { Dipping } \\
\text { time (s) }\end{array}$ & $\begin{array}{c}\text { Original } \\
\text { thickness }(\mathrm{nm})\end{array}$ & $\begin{array}{c}\text { Thickness after surface } \\
\text { treatment }(\mathrm{nm})\end{array}$ & $\begin{array}{c}\text { FTIR peak } \\
\text { position }\left(\mathrm{cm}^{-1}\right)\end{array}$ \\
\hline \multirow[t]{4}{*}{1.} & \multirow[t]{4}{*}{$0 \cdot 1$} & 5 & \multirow[t]{4}{*}{$14.6 \sim 14.9$} & 14.5 & $1070 \cdot 98$ \\
\hline & & 15 & & $14 \cdot 3$ & $1071 \cdot 15$ \\
\hline & & 30 & & $13 \cdot 0$ & $1070 \cdot 80$ \\
\hline & & 60 & & $14 \cdot 6$ & $1070 \cdot 98$ \\
\hline \multirow[t]{4}{*}{2.} & \multirow[t]{4}{*}{$0 \cdot 3$} & 5 & \multirow[t]{4}{*}{$13 \cdot 9 \sim 14 \cdot 4$} & $12 \cdot 59$ & $1070 \cdot 75$ \\
\hline & & 15 & & $13 \cdot 5$ & $1070 \cdot 91$ \\
\hline & & 30 & & $13 \cdot 0$ & $1068 \cdot 53$ \\
\hline & & 60 & & $11 \cdot 7$ & $1070 \cdot 91$ \\
\hline \multirow[t]{4}{*}{3.} & \multirow[t]{4}{*}{0.5} & 5 & \multirow[t]{4}{*}{$14.6 \sim 14.9$} & $14 \cdot 7$ & 1070.99 \\
\hline & & 15 & & $13 \cdot 6$ & $1068 \cdot 22$ \\
\hline & & 30 & & $13 \cdot 2$ & 1070.93 \\
\hline & & 60 & & 11.4 & $1068 \cdot 03$ \\
\hline
\end{tabular}

Table 2. Various processes carried out on $\mathrm{SiO}_{2}$ substrates.

\begin{tabular}{|c|c|c|}
\hline $\begin{array}{l}\text { Sample } \\
\text { code }\end{array}$ & Treatment before LPCVD & $\begin{array}{l}\text { Treatment after } \\
\text { LPCVD }\end{array}$ \\
\hline Sample 1 & Without surface treatment & Without annealing \\
\hline Sample 2 & Without surface treatment & Argon annealing \\
\hline Sample 3 & $1 \% \mathrm{HF}$ dip for $5 \mathrm{~s}$ & Without annealing \\
\hline Sample 4 & $1 \% \mathrm{HF}$ dip for $5 \mathrm{~s}$ & Argon annealing \\
\hline Sample 5 & $0.5 \% \mathrm{HF}$ dip for $30 \mathrm{~s}$ & Without annealing \\
\hline Sample 6 & $0.5 \% \mathrm{HF}$ dip for $30 \mathrm{~s}$ & Argon annealing \\
\hline Sample 7 & $0.5 \%$ HF dip for $30 \mathrm{~s}, \mathrm{RTP}$ & Argon annealing \\
\hline Sample 8 & $0.5 \% \mathrm{HF}$ dip for $30 \mathrm{~s}$ RTP & Without annealing \\
\hline Sample 9 & $0.5 \% \mathrm{HF}$ dip for $30 \mathrm{~s}$ & RTP \\
\hline Sample 10 & $0.5 \%$ HF dip for $30 \mathrm{~s}, \mathrm{RTP}$ & RTP \\
\hline
\end{tabular}

$5,15,30$ and $60 \mathrm{~s}$ followed by rinsing in deionized water to form $\mathrm{Si}-\mathrm{OH}$ bonds on $\mathrm{SiO}_{2}$ substrate (table 1). Surfacetreated samples were annealed at $850{ }^{\circ} \mathrm{C}$ using RTP (ASONE 150, ANNEALSYS) for 5 min to study its effect on the number of $\mathrm{Si}-\mathrm{OH}$ bonds.

\section{3 a-Si thin film deposition by LPCVD}

Surface-treated samples are transferred for LPCVD (Ultech furnace) to deposit $a$-Si film at $550{ }^{\circ} \mathrm{C}$ for $30 \mathrm{~min}$ at 0.2 torr pressure and $80 \mathrm{sccm}$ gas flow rate of silane. Amorphous thin film of $10 \mathrm{~nm}$ thickness was obtained which was then subjected to annealing/RTP to convert it into QD.

\subsection{Final heat treatment}

The $a$-Si thin film was (a) annealed at $850{ }^{\circ} \mathrm{C}$ for $20 \mathrm{~min}$ and (b) annealed at $850^{\circ} \mathrm{C}$ using RTP for 5 min to obtain Si QDs. Experimental details to prepare set of samples with varying heat treatments before and after LPCVD are given in table 2.
Figure 1 shows flow diagram of the experiment carried out in present work.

\subsection{Characterization techniques}

$\mathrm{Si}-\mathrm{OH}$ bonds formed after surface treatment were observed using FTIR (Spectrum BX II, Perkin Elmer). Ellipsometry (SE 800, SENTECH) was used to measure the initial thickness of $\mathrm{SiO}_{2}$ film formed after oxidation as well as the final thickness of film after HF treatment for different time periods. The images of Si QD were taken by SEM (6400 SEM, JOEL) and AFM (Dimension 3100 AFM, VEECO) and QD size distribution was studied by Auxiovision release 4.6.3 image analyser software. PL study was carried out with PC spectrofluorophotometer (RF 5301, Shimadzo).

\section{Results and discussion}

\subsection{Optimization of surface treatment}

The effect of surface treatment on number of $\mathrm{Si}-\mathrm{OH}$ bonds observed using FTIR and reduction of thickness using ellipsometry is shown in table 1 .

3.1a FTIR results: A broad band observed at 3550$3740 \mathrm{~cm}^{-1}$ corresponds to $\mathrm{O}-\mathrm{H}$ stretching and a weak peak between 1490 and $1560 \mathrm{~cm}^{-1}$ corresponds to $\mathrm{O}-\mathrm{H}$ bending (Suquet 1989). A strong peak at $\sim 1070 \mathrm{~cm}^{-1}$ indicates the presence of Si-O-Si stretching (Gencer Imer et al 2010). A weak peak at $\sim 810 \mathrm{~cm}^{-1}$ corresponds to $\mathrm{Si}-\mathrm{O}$ bending (Mestanza et al 2006) and at $\sim 590 \mathrm{~cm}^{-1}$ shows the presence of out of plane $\mathrm{Si}-\mathrm{O}$ stretching (Suquet 1989). Thus it confirms the formation of $\mathrm{Si}-\mathrm{OH}$ bonds after surface treatment.

As the etching time and concentration of HF increases, the number of $\mathrm{Si}-\mathrm{OH}$ bonds on substrate increases as 


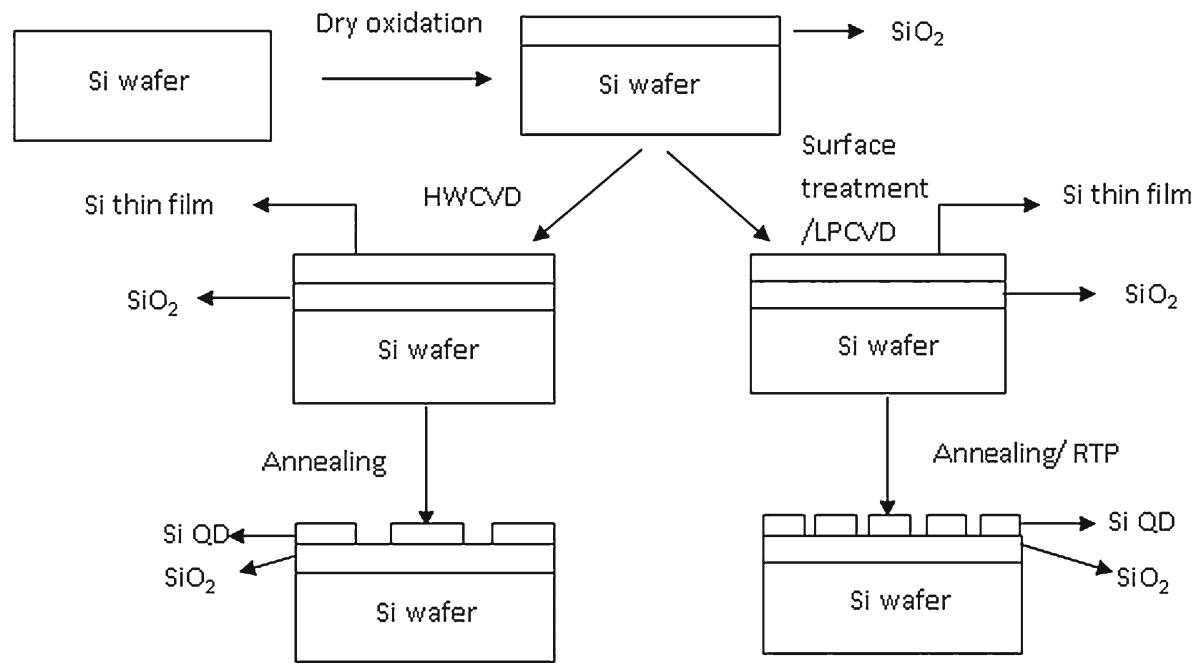

Figure 1. Experimental procedure for fabrication of Si QD.

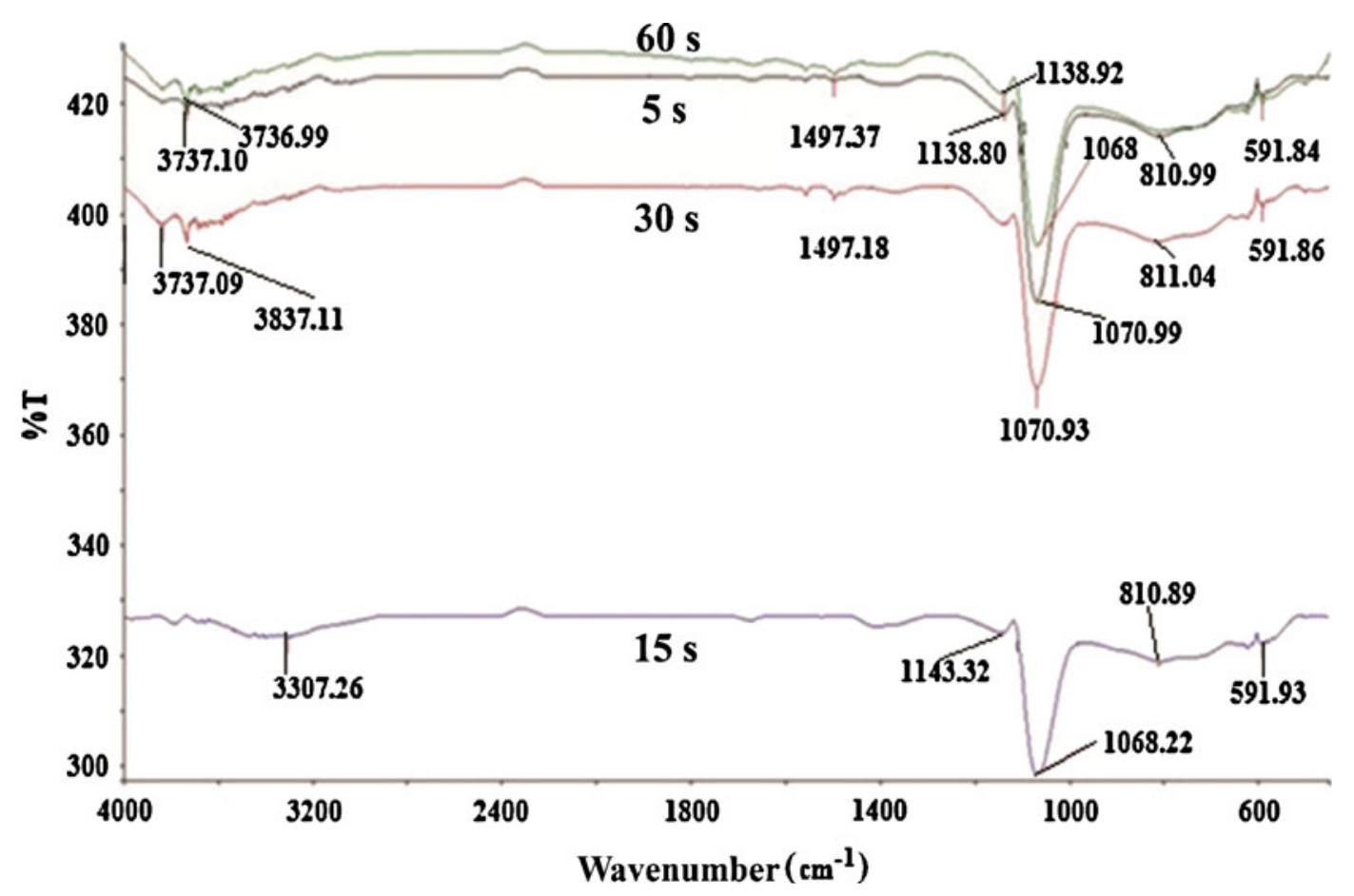

Figure 2. FTIR spectra of wafer dipped for 5, 15, 30 and $60 \mathrm{~s}$ in $0 \cdot 5 \%$ HF solution.

indicated by broad peak in between the frequency range 3550 and $3730 \mathrm{~cm}^{-1}$ shown in figure 2. Reaction taking place on surface due to HF treatment is given below.

$$
\mathrm{Si}-\mathrm{O}-\mathrm{Si}+\mathrm{H}^{+}+\mathrm{HOH} \rightarrow 2(\mathrm{Si}-\mathrm{OH})+\mathrm{H}^{+} .
$$

According to above chemical reaction, it is easier to break $\mathrm{O}-\mathrm{H}$ bonds (bond energy $103.5 \mathrm{kcal} / \mathrm{mol}$ ) (Mazen et al 2003) in comparison with the high energy $\mathrm{Si}-\mathrm{O}$ bond $(193.5 \mathrm{kcal} / \mathrm{mol})$ (Mazen et al 2003) resulting in high density of nucleation sites. The broad band indicates presence of bridged silanol and shoulder at $\sim 3740 \mathrm{~cm}^{-1}$ indicates isolated silanol. Vicinal silanol are transformed into bridged silanol when bonded together by hydrogen bonds (Mazen et al 2003). The strong peak at $\sim 1070 \mathrm{~cm}^{-1}$ indicates $\mathrm{Si}-\mathrm{O}-\mathrm{Si}$ stretching. As the thickness of $\mathrm{SiO}_{2}$ thin film decreases, the peak at $1070 \mathrm{~cm}^{-1}$ shifts towards lower wavelength confirming results obtained from ellipsometer. Observed shift is due to change in $\mathrm{Si}-\mathrm{O}-$ $\mathrm{Si}$ bond angle occurring due to stresses in $\mathrm{SiO}_{2}$ film (Mazen et al 2003). As explained by Mazen, the intrinsic stresses are generated at $\mathrm{Si}-\mathrm{SiO}_{2}$ interface due to molar volume expansion of $\mathrm{Si}$ in $\mathrm{SiO}_{2}$ due to which stresses are minimum on $\mathrm{SiO}_{2}$ surface and increases at $\mathrm{Si}-\mathrm{SiO}_{2}$ interface. With $\mathrm{HF}$ treatment, the surface is chemically attacked thereby decreasing the thickness of film and exposing the stressed region. 


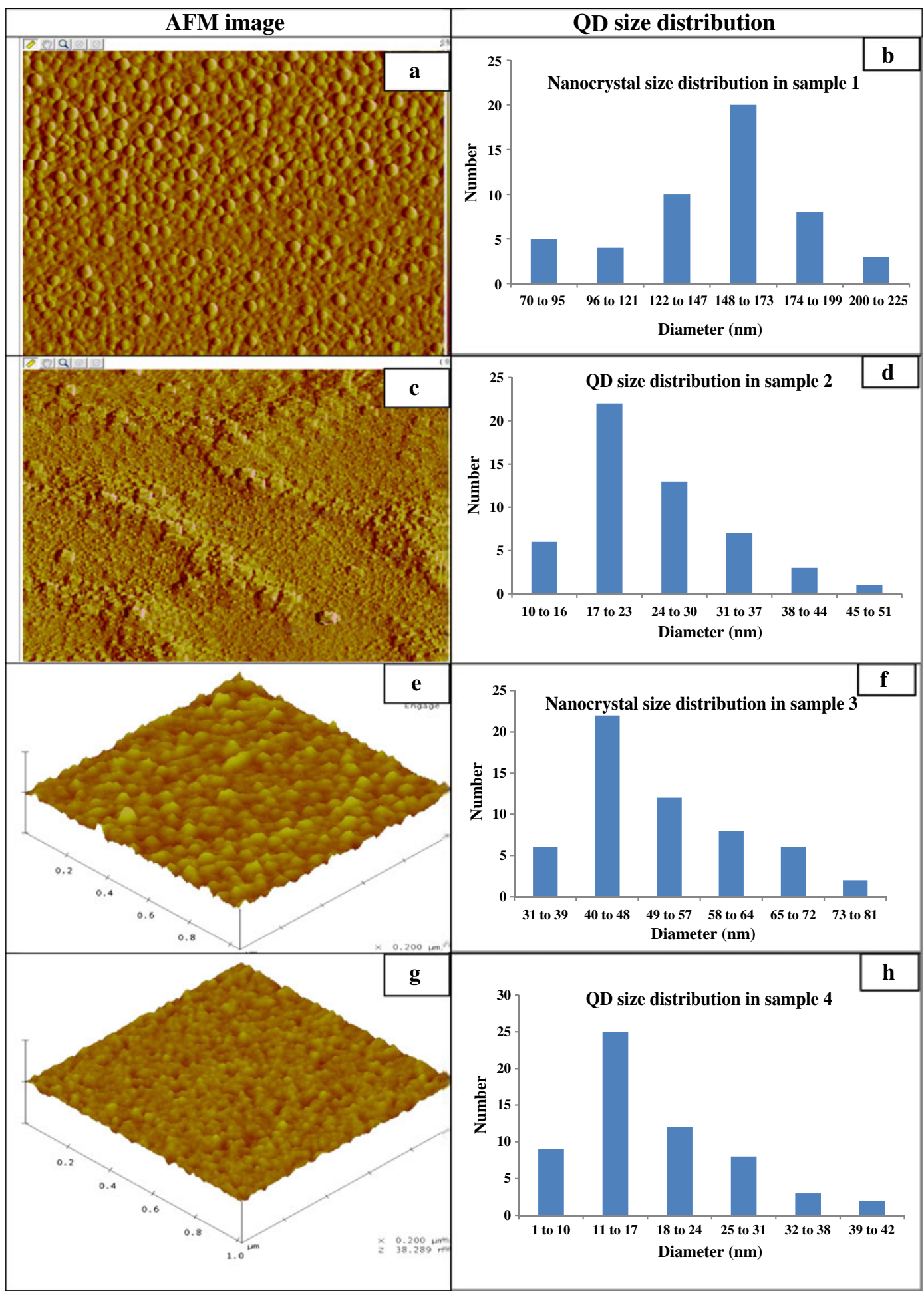

Figure 3. (a) AFM image of sample 1: no treatment + LPCVD + without annealing; (b) nanostructure size distribution in sample 1; (c) AFM image of sample 2: no treatment + LPCVD + annealing; (d) QD size distribution in sample 2; (e) AFM image of sample 3: HF treatment + LPCVD + without annealing; (f) nanostructure size distribution in sample 3; (g) AFM image of sample 4: HF treatment + LPCVD + annealing and (h) QD size distribution in sample 4.

3.1b Ellipsometry results: Mostly in the present study, it is observed that as the thickness of $\mathrm{SiO}_{2}$ thin film decreases, the peak at $1070 \mathrm{~cm}^{-1}$ shifts towards the low wavelength side.
Table 1 shows ellipsometry results and FTIR peak position of $\mathrm{Si}-\mathrm{O}-\mathrm{Si}$ stretching for different samples dipped in HF solution of different concentrations for varying times. In general, 
as the film thickness decreases, FTIR peak shift is expected towards lower wavelength but this is not observed in present case (table 1). This mismatch observed could be due to difference in thickness of deposited layer. The optimized concentration of $\mathrm{HF}$ used for surface treatment is $0.5 \% \mathrm{HF}$ applied for $30 \mathrm{~s}$ on $\mathrm{SiO}_{2}$ surface due to which the maximum formation of $\mathrm{Si}-\mathrm{OH}$ bonds takes place as seen by sharp peak at $3737.09 \mathrm{~cm}^{-1}$ associated with isolated silanol bonds.

\subsection{AFM images}

3.2a Effect of annealing on formation of $Q D$ : To understand the effect of annealing on HF treated and non-treated on $\mathrm{SiO}_{2}$ surface, a separate study is carried out as shown in table 2 for samples 1, 2, 3 and 4. AFM images of samples 1, 2, 3 and 4 are shown in figure 3(a, c, e and g), respectively while figure $3(\mathrm{~b}, \mathrm{~d}, \mathrm{f}$ and $\mathrm{h}$ ) are in the form of histograms

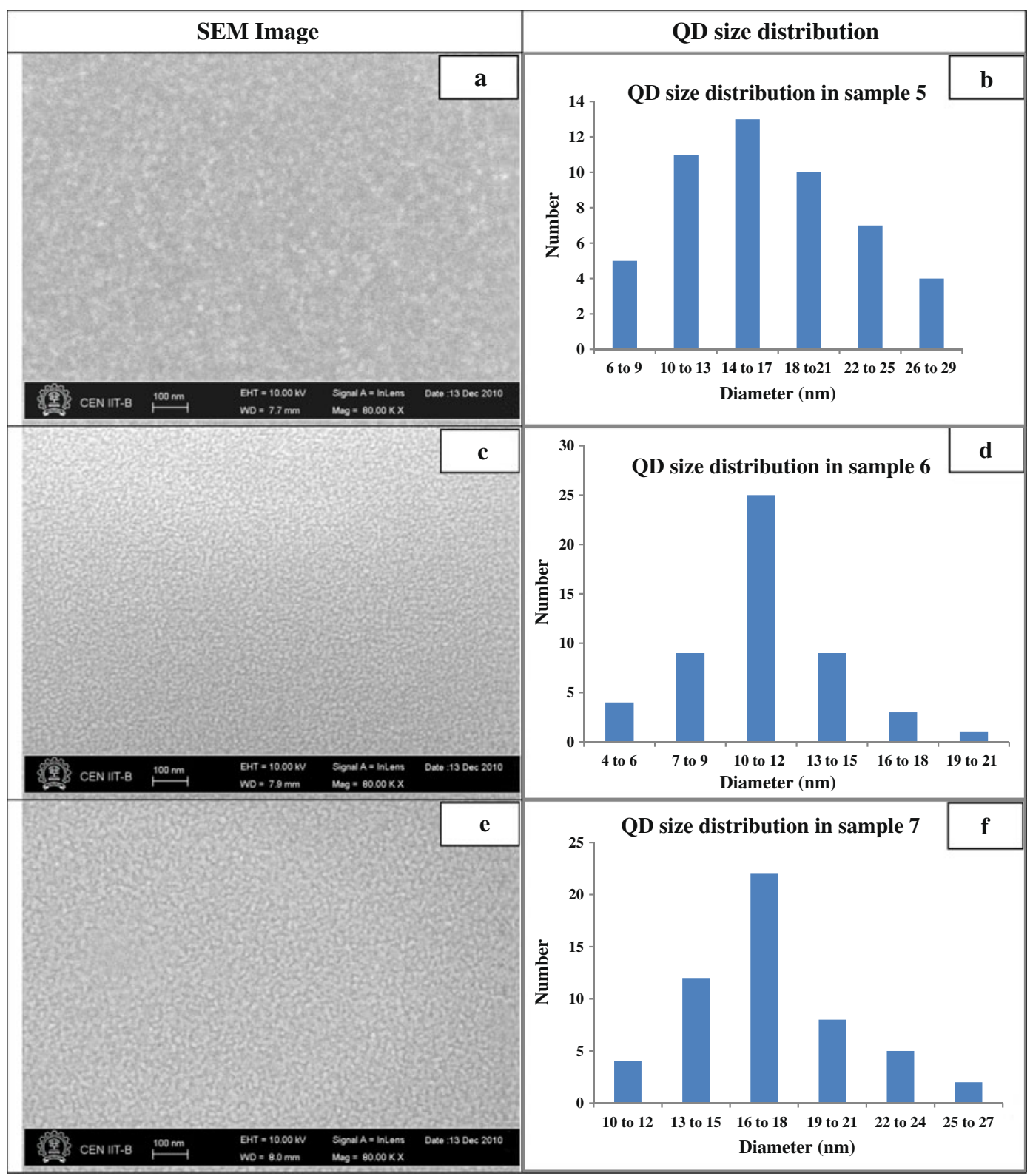

Figure 4. (a) SEM image of sample 5: HF treatment + LPCVD + without annealing; (b) QD size distribution in sample 5; (c) SEM image of sample 6: HF treatment + LPCVD + Ar annealing; (d) QD size distribution in sample 6; (e) SEM image of sample 7: HF treatment + RTP + LPCVD + Ar annealing; (f) QD size distribution in sample 7; (g) SEM image of sample 8: HF treatment + RTP + LPCVD + without annealing; (h) SEM image of sample 9: HF treatment + LPCVD + RTP and (i) SEM image of sample 10: HF treatment + RTP + LPCVD. 


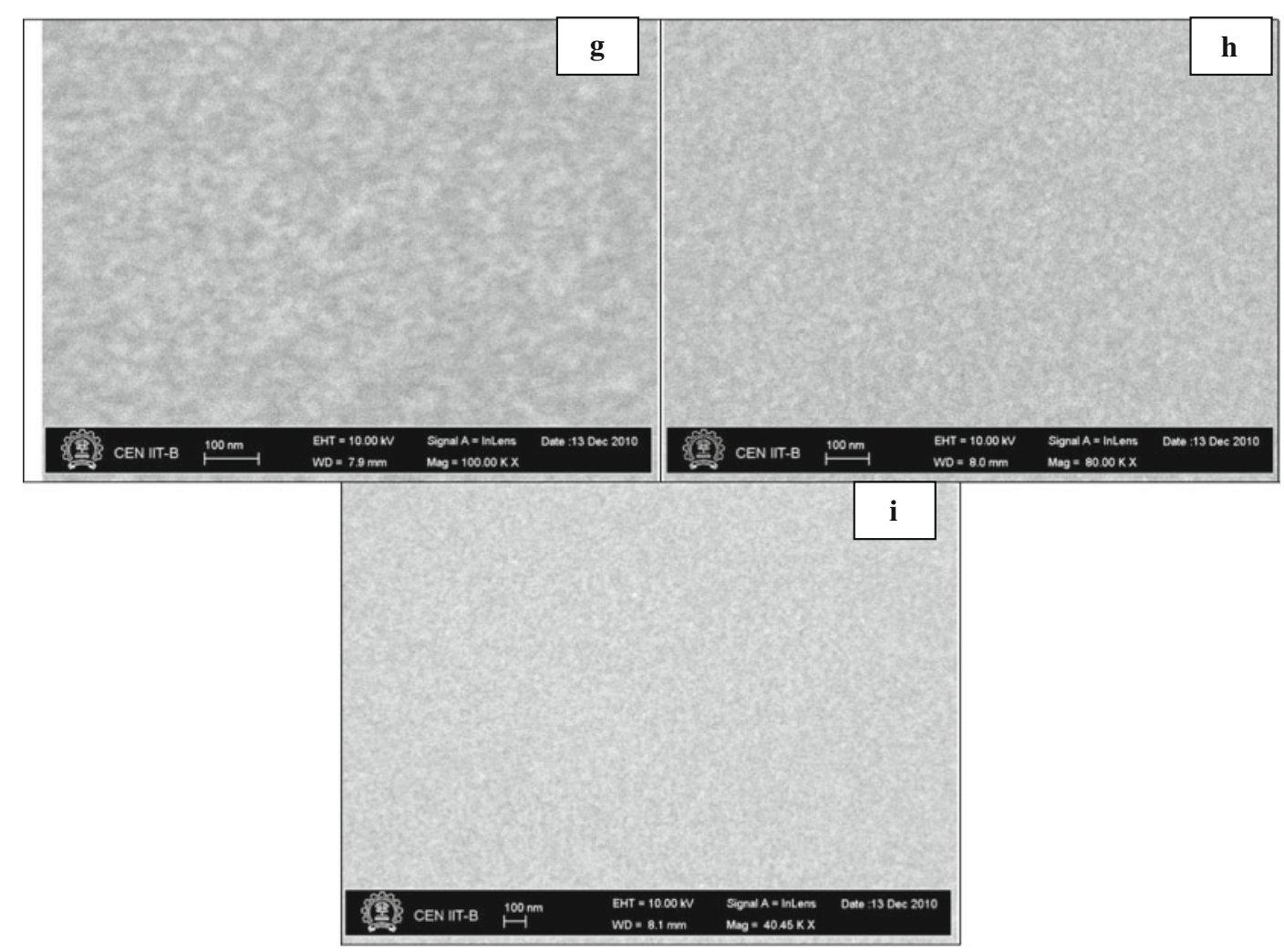

Figure 4. (contd.)

showing distribution of QDs/nanocrystal. Sample 1 is without surface treatment and annealing showing nanostructure having dimension above $100 \mathrm{~nm}$ (figures $3 \mathrm{a}$ and $\mathrm{b}$ ). In sample 2, argon annealing is done without prior HF treatment on $\mathrm{SiO}_{2}$ substrate. QDs formed in sample 2 have dimension in the range of $17-21 \mathrm{~nm}$ (figures $3 \mathrm{c}$ and d). Processing of sample 3 includes prior HF treatment to $\mathrm{SiO}_{2}$ film while $\mathrm{Si}$ thin film deposited is not annealed resulting in the nanostructure formation in the range $40-48 \mathrm{~nm}$ (figures $3 \mathrm{e}$ and f). Finally, for sample 4 which is surface treated and annealed, QD dimension in the range of $11-7 \mathrm{~nm}$ (figures $3 \mathrm{~g}$ and $\mathrm{h}$ ) is obtained. The combined effect of surface treatment and annealing resulted in the reduction of QD size. Surface treatment has produced high density $\mathrm{Si}-\mathrm{OH}$ bonds which acts as nucleation sites for deposition of $\mathrm{Si}$ and further annealing results in recrystallization to form high density homogeneous Si QD throughout the surface.

\subsection{SEM results}

3.3a Effect of annealing on formation of QD: Figure 4(a, $\mathrm{c}$ and e) shows SEM images of samples 5, 6 and 7, while figure 4(b, $d$ and f) are the respective QD size distribution histograms of these samples. The dimensions of QD formed in sample 5 are in the range of $10-30 \mathrm{~nm}$ (figures $4 \mathrm{a}, \mathrm{b}$ ) which could be due to absence of annealing treatment while in sample 6, the majority QD size are found to be of $10 \mathrm{~nm}$ (figures $4 \mathrm{c}, \mathrm{d})$ by annealing after LPCVD. The reason for small size obtained is explained above using AFM results. It is observed that RTP prior to LPCVD results in increase in size of Si QD which is nearly $16-18 \mathrm{~nm}$ in case of sample 7 (figure 4(e and f)). Reason could be due to RTP, number of $\mathrm{Si}-\mathrm{OH}$ bonds gets reduced due to the removal of water molecules resulting in the decrease of nucleation sites and hence small increase in the size of QD.

3.3b Effect of RTP on formation of QD: SEM images of samples 7, 8, 9 and 10 are shown in figure 4(e, g, h and i), respectively. It is observed that RTP prior to LPCVD (sample 7) can be used to control the density and size of QDs. Annealing is not done for sample 8 resulting in large size of QD formed in comparison with other samples (figure 4(g)). RTP carried out after LPCVD in case of samples 9 and 10 is not enough to convert $\mathrm{Si}$ thin film into discrete QD (figure 4(h and i)), this may be due to less time available for recrystallization for rearrangement of $\mathrm{Si}$ atoms.

Thus, sample undergoing argon annealing after LPCVD results in uniform QDs as compared to sample undergoing RTP after LPCVD. But RTP prior to LPCVD can be used to get required size and density of QD.

\subsection{Photoluminescence spectra of sample}

3.4a Effect of annealing on formation of $Q D$ : When samples 5 and 6 are excited with wavelength of $352 \mathrm{~nm}$ (figure 5 ), emission spectrum is observed at wavelengths of 388 , 438 and $471 \mathrm{~nm}$ in the former which indicates varying QD 


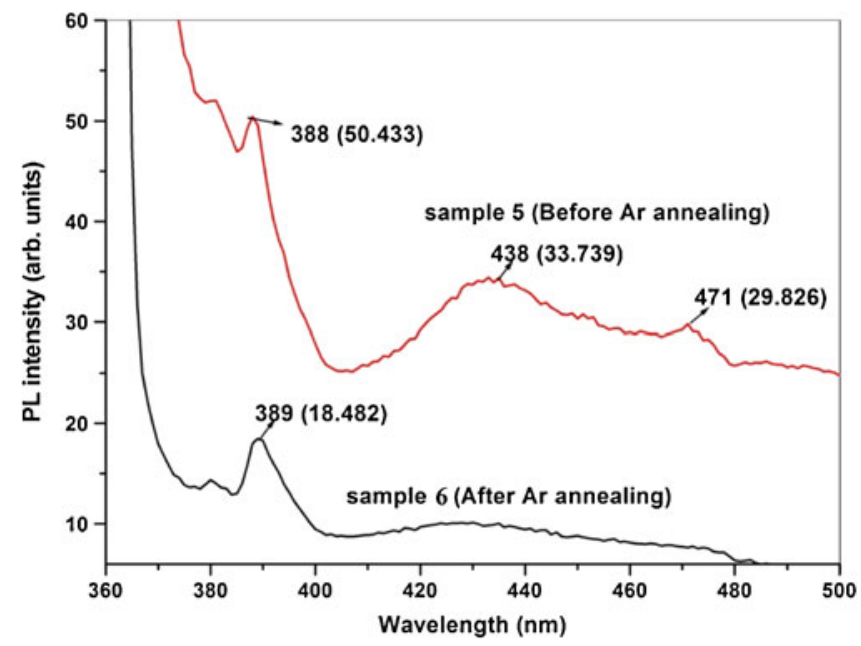

Figure 5. PL spectrum showing effect of Ar annealing on size distribution of QD.

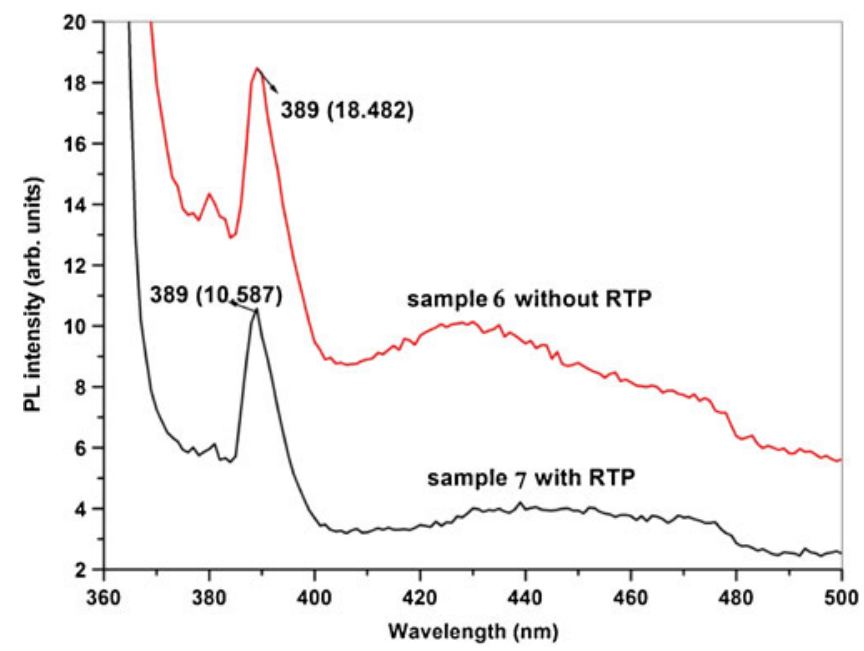

Figure 6. PL spectrum showing effect of RTP on density of QD.

size distribution since the sample is not annealed, whereas latter shows emission only at $389 \mathrm{~nm}$ indicating uniform-sized QD. This can be confirmed from QD size distribution histograms of samples 5 and 6 , respectively (figures $4 \mathrm{~b}$ and d). In case of sample 5, majority QD formed are in the range $10-13,14-17$ and $18-21 \mathrm{~nm}$ corresponding to emissions at 388,438 and $471 \mathrm{~nm}$ wavelength. In case of sample 6, majority of QD are in the range 10-12 $\mathrm{nm}$ and hence shows emission only at $389 \mathrm{~nm}$. Overall larger QD (>20 nm) gets converted into smaller dimension in the range $10-20 \mathrm{~nm}$ because of re-crystallization at high temperature annealing. Annealing decreases the stress developed during the deposition of Si thin film on $\mathrm{SiO}_{2}$ substrate.

3.4b Effect of RTP on formation of $Q D$ : The photoluminescence spectra (figure 6) of samples give similar information as SEM images (figures $4 c$ and d). PL intensity of sample 6 is greater than sample 7 which indicates that the

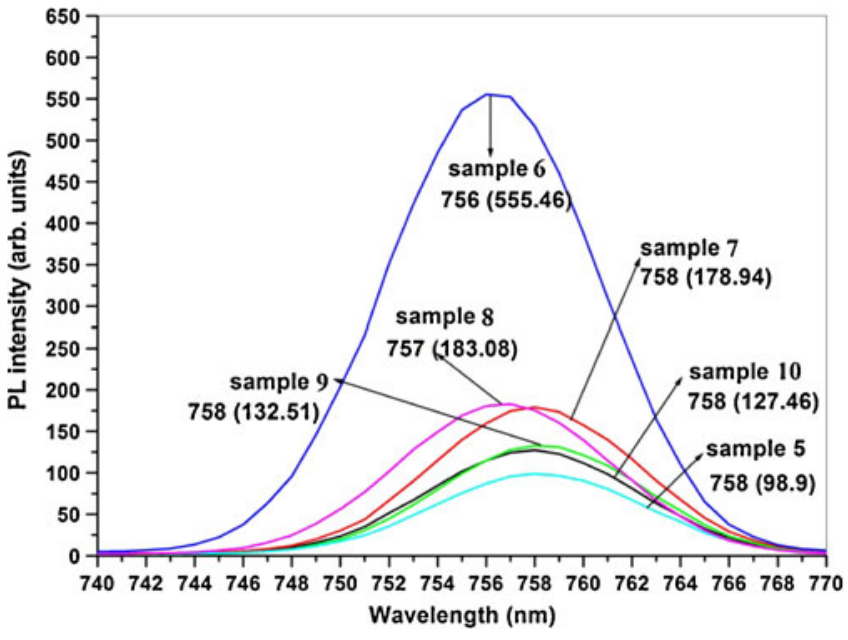

Figure 7. Comparative photoluminescence study of samples prepared by LPCVD (excitation wavelength: $500 \mathrm{~nm}$ ).

density of QD in sample 6 is higher than sample 7. The decrease in density due to RTP in case of sample 7 is because of decrease in $\mathrm{Si}-\mathrm{OH}$ bonds/silanol groups which acts as nucleation site for formation of Si QD. Adjacent silanol gets converted into $\mathrm{Si}-\mathrm{O}-\mathrm{Si}$ and water molecule resulting in the reduced nucleation sites which in fact decreases density of QD. As the quantity of QDs increases, the number of electron hole pair recombination on silicon surface also increases (Qin and Jia 1993) which increases the intensity of PL spectra. Blue shift is observed due to decrease in wavelength in case of sample 6 which indicate decrease in QD size in comparison with other samples (figure 7). The smallest QDs of dimension 10-12 $\mathrm{nm}$ are formed in case of sample 6 (figures $4 \mathrm{c}$ and d) which is similar to results obtained by Fauchet (1996).

\section{Conclusions}

Surface treatment given to $\mathrm{SiO}_{2}$ substrate develops $\mathrm{Si}-\mathrm{OH}$ bonds which act as nucleation sites to increase the density of Si. Argon annealing results in small size uniform QDs. RTP decreases the density and increases the size of QD as compared to that obtained by annealing. The blue shift observed in PL spectra indicates the decrease in size of QD. The emission spectra observed in red frequency region indicates that quantum confinement takes place in sample and confirms the formation of Si QD. Hence QDs fabricated using present process can be adopted in electronic devices manufacturing for performance enhancement.

\section{Acknowledgements}

Authors are thankful to Ministry of Communication and Information Technology, Government of India, for funding and INUP, Indian Institute of Technology, Bombay, for supporting this research work. 


\section{References}

Adachi M M 2007 Low temperature thin film silicon solar cells prepared by hot wire chemical vapour deposition, Master of Applied Sciences, Simon Fraser University, Canada

Fauchet P M 1996 J. Lumin. 70294

Geller M, Marent A, Nowozin T, Feise D, Potschke K, Akcay N, Oncan N and Bimberg D 2008 Physica E 401811

Gencer Imer A, Yerci S, Alagoz A S, Kulakci M, Serincan U, Finstad T G and Turan R 2010 J. Nanosci. Nanotechnol. 10525 Grundmann M et al 1998 Thin Solid Films 31883

Knoss R W 2009 Quantum dots: Research technology and applications (New York: Nova Science Publishers Inc.) ch. 1 , p. 1

Makihara K, Deki H, Murakami H, Higashi S and Miyazaki S 2005 Appl. Surf. Sci. 24475

Matsumura 1986 Jpn. J. Appl. Phys. 25 L949
Mazen F, Baron T, Bremond G, Buffet N, Rochat N, Mur P and Semeria M N 2003 J. Electrochem. Soc. 150 G203

Mercaldo L V, Veneri P D, Emilia Esposito, Ettore Massera, Iurie Usatii and Carlo Privato 2009 Mater. Sci. Eng. B159-160 77

Mestanza, Obrador S N M, Rodriguez M P, Biasotto E, Doi C, Diniz I and Swart J A 2006 J. Vac. Sci. Technol. B24 823

Miyazaki S, Hamamoto Y, Yoshida E, Ikeda M and Hirose M 2000 Thin Solid Films $\mathbf{3 6 9} 55$

Pant A and Russell T W F 2001 Ind. Eng. Chem. Res. 401377

Qin G G and Jia Y Q 1993 Solid State Commun. 86559

Soon J O, Yook K S, Joo C W and Lee J Y 2009 J. Ind. Eng. Chem. 15602

Suquet H 1989 Clays Clay Miner. 37439

Wiesmann H, Ghosh A K, McMahon T and Strongin M 1979 J. Appl. Phys. $\mathbf{5 0} 3752$

Zhao Zhouying, Arrandale Mayrita, Vassiltsova Oxana V, Marina A and Carpenter Michael A 2009 Sens. Actuators B141 26 